\title{
ESCARIFICAÇÃO QUÍMICA PARA A SUPERAÇÃO DA DORMÊNCIA DE SEMENTES DE SAGUARAJI-VERMELHO (Colubrina glandulosa PERK. - RHAMNACEAE) ${ }^{1}$
}

Pedro Henrique Santin Brancalion², Vitor Henrique Vaz Mondo ${ }^{3}$ e Ana Dionísia da Luz Coelho Novembre ${ }^{4}$

RESUMO - Este trabalho objetivou avaliar diferentes períodos de imersão de sementes de saguaraji-vermelho (Colubrina glandulosa) em ácido sulfúrico, para a superação da dormência. O experimento foi dividido em duas etapas. Na primeira, sementes de cinco lotes provenientes de diferentes localidades (dois recém-coletados e os demais armazenados por um, dois e três anos) foram escarificadas quimicamente com ácido sulfúrico concentrado por 30, 60, 90, 120 e $150 \mathrm{~min}$. Na segunda etapa, as sementes dos lotes recém-coletados foram imersas em ácido por 20, 30, 40, 50 e 60 min. As sementes escarificadas com ácido e as não escarificadas foram avaliadas diariamente quanto à germinação (rolo de papel, $25^{\circ} \mathrm{C}$, no escuro e quatro repetições de 25 sementes por tratamento) - com os dados, foram calculadas sua porcentagem e velocidade. Na primeira fase, as médias dos tratamentos foram comparadas pelo teste de Tukey $(\mathrm{P} \leq 0,05)$ e na segunda, por equações de regressão. Os resultados indicaram que a porcentagem de dormência variou entre as sementes dos lotes (taxas mais altas das sementes recém-colhidas), e a escarificação com ácido por 30 a 90 min foi favorável à superação da dormência. Houve prejuízo na germinação com a escarificação das sementes por 120 min e 150 min. Na segunda fase, valores máximos de porcentagem e velocidade de germinação foram obtidos após 60 min de imersão. Diante desses resultados, o armazenamento por um ano e a imersão das sementes em ácido sulfúrico por 30 a 90 min podem ser utilizados, com eficiência, para a superação da dormência de sementes de saguaraji-vermelho.

Palavras-chave: Sementes florestais. Germinação, Armazenamento, Sementes duras e Tegumento impermeável à água.

\section{CHEMICAL SCARIFICATION TO OVERCOME DORMANCY ON Colubrina glandulosa PERK. (RHAMNACEAE) SEEDS}

\begin{abstract}
This work aimed to evaluate different immersion periods of Colubrina glandulosa seeds in sulfuric acid for overcoming dormancy. The experiment was divided into two phases. In the first, five seed lots harvested in different localities (two recently harvested and the others in 2004, 2005 and 2006), were chemically scarified in concentrated sulfuric acid for 30, 60, 90,120 and 150 minutes. In the second phase seeds from recently harvested lots were immersed in acid for 20, 30, 40, 50 and 60 minutes. Germination of scarified in acid and non scarified seeds was evaluated daily (paper roll, $25^{\circ} \mathrm{C}$, darkness and four replicates of 25 seeds per treatment) and, with the data, germination percentage and speed were calculated. In the first phase means were compared by the Tukey test $(P \leq 0.05)$ and in the second the treatments were compared by regressive equations. Results showed that dormancy percentage varied among seed lots (higher intensity for recently harvested seeds) and that scarification in acid for a period between 30 and 90 minutes was favorable for overcoming dormancy. Germination was negatively affected when seeds were scarified for 120 or 150 minutes. In the second phase the maximum values of germination percentage and speed were obtained after immersion for 60 minutes. Based on such results, seed storage for 1 year and immersion in sulfuric acid for a period between 30 and 90 minutes can be efficiently used to overcome C. glandulosa seed dormancy.
\end{abstract}

Key words: Forest seeds, Storage, Germination, Seed hardness and Impermeable seed coat.

\footnotetext{
${ }^{1}$ Recebido em 18.06.2008 e aceito para publicação em 25.08.2010.

${ }^{2}$ Universidade de São Paulo, USP, Brasil. E-mail: <pedrob@usp.br>.

${ }^{3}$ Monsanto do Brasil Ltda., MON, Brasil. E-mail: <vhvmondo@yahoo.com.br>.

${ }^{4}$ Universidade de São Paulo, USP, Brasil. E-mail: <adlcnove@esalq.usp.br>.
} 


\section{INTRODUÇÃO}

Em ambientes naturais, a dormência de sementes representa recurso eficaz para a perpetuação das espécies, conferindo à semente resistência às condições desfavoráveis do ambiente e distribuindo a germinação no tempo (FOWLER e BIANCHETTI, 2000).

Além dos fatores intrinsecamente relacionados à semente, resultado das condições ambientais durante a maturação (GUTTERMAN, 2000), do posicionamento da semente na planta-mãe (FORSYTHE e BROWN, 1982; HENDRIX, 1984) e da procedência (QUEIROZ et al., 2000), a intensidade da dormência pode ser afetada pelo tempo de armazenamento e pelas condições em que este é realizado (MARCOS FILHO, 2005). No caso das sementes com tegumento impermeável à água, a intensidade da dormência diminui progressivamente ao longo do armazenamento, chegando a ponto de dispensar tratamentos para sua superação (FERREIRA et al., 1992). Mesmo nas sementes de um lote recém-colhido pode haver sementes com impermeabilidade do tegumento à água e sementes que absorvem água sem a restrição imposta pelo tegumento (EIRA et al., 1993).

Embora essa intensidade variável da dormência aumente as chances de sobrevivência da espécie, ela representa obstáculo ao estabelecimento de métodos padronizados para a superação da dormência, o que dificulta a análise de sementes e a produção de mudas em viveiros florestais. Diante do exposto, evidenciase que o estabelecimento de determinado método para a superação da dormência deve contemplar todas essas possíveis variações, permitindo que a maioria das sementes vivas e dormentes expresse seu potencial fisiológico após a aplicação do método, apresentando germinação rápida e uniforme, sem prejudicar a germinação das sementes não dormentes.

Entre os métodos utilizados para a superação da dormência tegumentar de sementes de espécies arbóreas brasileiras, destaca-se a escarificação química com ácido sulfúrico (OLIVEIRA et al., 2003; SMIDERLE e SOUSA, 2003; LOPES et al., 2006). Esse método pode ser particularmente importante em espécies com sementes pequenas, já que, nesse caso, a escarificação mecânica do tegumento não é exequível.

A partir da expansão dos projetos de restauração florestal tem aumentado a demanda por sementes de espécies nativas que existem nas diferentes formações florestais brasileiras. Entretanto, para boa parte dessas espécies, ainda não há métodos adequados para a coleta, beneficiamento, armazenamento e superação da dormência, o que limita a disponibilidade e uso das sementes, dificulta a produção de mudas e, consequentemente, compromete a implantação de reflorestamentos visando à restauração florestal.

Entre essas espécies, destaca-se o saguarajivermelho (Colubrina glandulosa Perkins - Rhamnaceae), que tem forte dormência tegumentar (CARVALHO, 1994) relacionada à sua impermeabilidade à água. Essa espécie possui potencial para ser utilizada em projetos de restauração florestal em várias regiões do Brasil, em virtude de sua amplitude de ocorrência geográfica, estando presente desde o Estado do Ceará até o Rio Grande do Sul, na Floresta Pluvial Atlântica, nos Estados de Minas Gerais, Goiás, São Paulo e Paraná, na Floresta Estacional Semidecidual, no Estado de Mato Grosso do Sul, no Cerradão, e na Restinga de vários estados (CARVALHO, 1994; LORENZI, 2002).

Dessa forma, este trabalho objetivou avaliar a escarificação química com ácido sulfúrico para a superação da dormência das sementes de saguaraji-vermelho (Colubrina glandulosa Perk.).

\section{MATERIAL E MÉTODOS}

Foram utilizadas sementes de saguaraji-vermelho (Colubrina glandulosa Perk.) coletadas em Ibaté, SP, e armazenadas por três anos em câmara seca e fria ( $15^{\circ} \mathrm{C}$ e $50 \%$ de umidade relativa do ar), em tambores de papelão (lote 1); coletadas em Orlândia, SP, e armazenadas por dois anos em condições não controladas de ambiente, em sacos de papel (lote 2); coletadas em Ribeirão Grande, SP, e armazenadas por um ano em condições não controladas de ambiente, em sacos de papel (lote 3); coletadas em Serrana, SP, e utilizadas logo após a coleta (lote 4); e coletadas em Orlândia, SP, e utilizadas logo após a coleta (lote 5 ). As coletas foram realizadas nos meses de janeiro e fevereiro, sendo esse o período de dispersão natural das sementes.

As infrutescências (Figura 1A) foram coletadas diretamente das árvores e posteriormente expostas ao sol para a abertura dos frutos, os quais são secos e deiscentes (Figura 1B), contendo três sementes cada (Figura 1C). As sementes de tegumento negro e brilhante que impede a absorção de água têm cerca de 3 mm de diâmetro, 4 mm de comprimento e $2 \mathrm{~mm}$ de espessura (Figura 1D). 


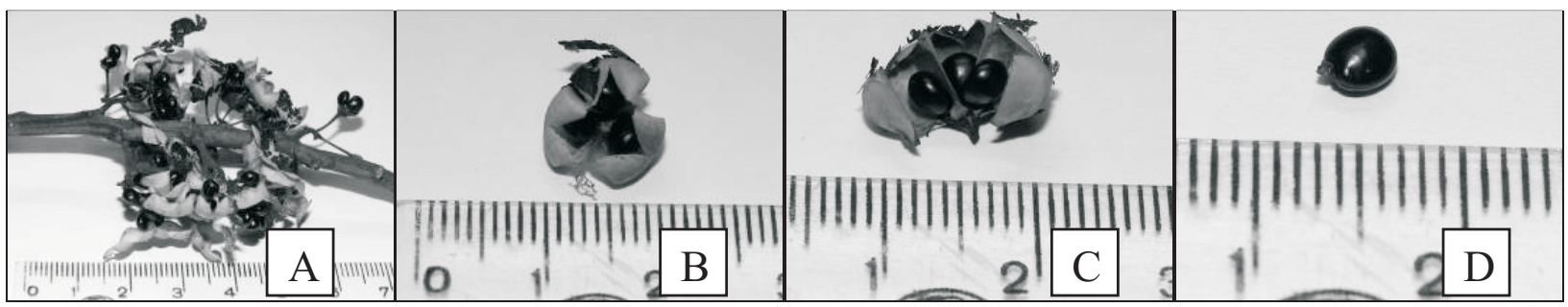

Figura 1 - Infrutescências (A), abertura do fruto seco e deiscente (B), fruto contendo três sementes (C) e semente (D) de saguaraji-vermelho (Colubrina glandulosa Perk.).

Figure 1 - Fructescence (A), opening of dry and dehiscent fruits (B), fruit containing three seeds (C) and seed (D) of Colubrina glandulosa Perk.

$\mathrm{O}$ experimento foi dividido em duas etapas. $\mathrm{Na}$ primeira, as sementes dos cinco lotes-foram escarificadas quimicamente com ácido sulfúrico concentrado por 30, 60, 90, 120 e $150 \mathrm{~min}$. Com base nos resultados da primeira etapa, na segunda as sementes dos lotes 4 e 5 foram imersas em ácido por 20, 30, 40, 50 e 60 min. Um controle sem a imersão das sementes em ácido foi adotado. Na escarificação, as sementes foram colocadas em Becker de vidro e cobertas com volume de ácido correspondente ao dobro do volume delas. A cada $15 \mathrm{~min}$, as sementes imersas em ácido foram agitadas com o uso de um bastão de vidro. Transcorridos os períodos determinados, o excesso de ácido sulfúrico foi retirado, as sementes foram separadas em peneira e lavadas em água corrente por $10 \mathrm{~min}$. Após essa operação, as sementes foram colocadas para secar sobre papel-toalha e foram, em seguida, utilizadas na instalação do teste de germinação.

No teste de germinação, as sementes foram distribuídas sobre duas folhas de papel- toalha e cobertas com terceira folha desse tipo de papel, sendo as folhas posteriormente umedecidas com quantidade de água equivalente a 2,5 vezes a massa seca das folhas. $\mathrm{O}$ conjunto de folhas foi, então, enrolado (rolo de papel) e mantido na posição vertical em germinador a $25{ }^{\circ} \mathrm{C}$ (ALBUQUERQUE et al., 1998), no escuro. A germinação foi avaliada diariamente, por meio da contagem de plântulas normais (BRASIL, 1992).

Com os dados, foram calculados o índice de velocidade de germinação (IVG), de acordo com a fórmula descrita por Maguire (1962), e a porcentagem de germinação.

O delineamento experimental utilizado foi o inteiramente casualizado, com quatro repetições de 25 sementes por tratamento. Na primeira etapa, os dados obtidos no teste de germinação foram submetidos à análise de variância, e compararam-se das médias obtidas em cada lote e entre os lotes pelo teste de Tukey $(P \leq 0,05)$, eutilizando-se oprograma SANEST(ZONTAeMACHADO, 1984). Nas tabelas são apresentados os dados originais. Na segunda etapa, a comparação dos tratamentos foi realizada por equações de regressão.

\section{RESULTADOS E DISCUSSÃO}

Os resultados da primeira etapa da pesquisa estão apresentados na Tabela 1. Verificou-se que nos lotes armazenados pelo período de um a três anos (lotes 1 , 2 e 3) as sementes que permaneceram viáveis não estavam mais dormentes, dispensando a superação da dormência. Tais resultados evidenciaram o papel do armazenamento na superação da impermeabilidade do tegumento de sementes florestais à água. Mesmo nesse caso, o tratamento com ácido sulfúrico por até 90 min não foi prejudicial às sementes, exceto no lote 3 .

Já as sementes dos lotes 4 e 5 apresentavam dormência, a qual foi superada pela imersão em ácido sulfúrico por um período de 30 a $90 \mathrm{~min}$. Em todos os lotes, a escarificação química por 120 e 150 min foi prejudicial às sementes, diminuindo a percentagem e a velocidade de germinação.

A maior sensibilidade de sementes armazenadas ao ácido sulfúrico não foi observada, já que as sementes dos lotes analisados apenas foram prejudicadas pela escarificação química a partir da exposição por 120 min, a qual resultou na morte da maioria das sementes. A imersão das sementes em ácido sulfúrico por 120 e 150 min pode ter causado a degradação do tegumento da semente e do embrião. Entretanto, Queiroz (1982) e Ramos e Zanon (1986) recomendaram a escarificação química das sementes de saguaraji-vermelho com ácido sulfúrico por $120 \mathrm{~min}$, o que divergiu dos resultados desta pesquisa.

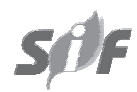

Revista Árvore, Viçosa-MG, v.35, n.1, p.119-124, 2011 
Tabela 1 - Germinação (\%) e índice de velocidade de germinação (IVG) de sementes de saguaraji-vermelho, lotes 1, 2, 3 , 4 e 5, não submetidas à escarificação ácida (zero) e escarificadas por 30, 60, 90, 120 e 150 min. Sementes dos lotes 1 , 2 e 3 foram armazenadas, respectivamente, por 3, 2 e 1 ano, ao passo que as dos lotes 4 e 5 eram recémcoletadas.

Table 1 - Germination (G\%) and germination speed (IVG) of Colubrina glandulosa Perk. seeds, lots 1, 2, 3, 4 and 5, not submitted to acid scarification (zero) and scarified for 30, 60, 90, 120 and 150 minutes. Seeds from lots 1, 2 and 3 were stored for, respectively, 3, 2 and 1 year, and seeds from lots 4 and 5 were recently harvested.

\begin{tabular}{|c|c|c|c|c|c|c|c|c|c|c|}
\hline \multirow{3}{*}{$\begin{array}{l}\text { Tempo de escarificação } \\
\text { das sementes em ácido } \\
\text { sulfúrico concentrado }\end{array}$} & \multicolumn{10}{|c|}{ Lotes } \\
\hline & \multicolumn{2}{|c|}{1} & \multicolumn{2}{|r|}{2} & \multicolumn{2}{|c|}{3} & \multicolumn{2}{|c|}{4} & \multicolumn{2}{|r|}{5} \\
\hline & $G(\%)$ & IVG & $\mathrm{G}(\%)$ & IVG & $G(\%)$ & IVG & $\mathrm{G}(\%)$ & IVG & G (\%) & IVG \\
\hline 0 minutos & $47 \mathrm{Aab}$ & 4,0 Aab & $39 \mathrm{Aab}$ & 3,3 Aab & $55 \mathrm{Aab}$ & $4,5 \mathrm{Abc}$ & $10 \mathrm{Bbc}$ & $0,8 \mathrm{Bb}$ & $0 \mathrm{Cc}$ & $0,0 \mathrm{Bb}$ \\
\hline 30 minutos & $53 \mathrm{ABa}$ & 4,8 АВа & $48 \mathrm{ABa}$ & $4,5 \mathrm{Ba}$ & $61 \mathrm{ABab}$ & 5,4 ABab & 73 Аа & 6,7 Аа & $42 \mathrm{Ba}$ & $5,4 \mathrm{ABa}$ \\
\hline 60 minutos & $57 \mathrm{ABa}$ & $5,6 \mathrm{Ba}$ & $38 \mathrm{Bab}$ & 3,7 Cab & 77Aa & 7,3 АВа & $80 \mathrm{Aa}$ & $8,0 \mathrm{Aa}$ & $72 \mathrm{Aa}$ & $6,5 \mathrm{ANa}$ \\
\hline 90 minutos & $58 \mathrm{aBa}$ & 5,6 ABa & $42 \mathrm{ABa}$ & 4,3 Ba & $40 \mathrm{Bb}$ & 3,9 Bbc & 70 Аа & 6,7 Аа & $57 \mathrm{ABa}$ & 5,6 ABa \\
\hline 120 minutos & $24 \mathrm{ABb}$ & $2,3 \mathrm{ABb}$ & $20 \mathrm{ABb}$ & 1,8 ABbc & $36 \mathrm{Ab}$ & $3,2 \mathrm{Ac}$ & $19 \mathrm{ABb}$ & $1,6 \mathrm{ABb}$ & $12 \mathrm{Bb}$ & $1,1 \mathrm{Bb}$ \\
\hline 150 minutos & $1 \mathrm{Ac}$ & $0,2 \mathrm{Ac}$ & $2 \mathrm{Ac}$ & $0,3 \mathrm{Ac}$ & $1 \mathrm{Ac}$ & $0,1 \mathrm{Ad}$ & $2 \mathrm{Ac}$ & $0,3 \mathrm{Ab}$ & $2 \mathrm{Ac}$ & $0,2 \mathrm{Ab}$ \\
\hline
\end{tabular}

Médias seguidas de mesma letra e letra maiúscula na linha e minúscula na coluna não diferem entre si, pelo teste de Tukey $(\mathrm{P} \leq 0,05)$.

Considerando que as sementes dos lotes 1 e 2 não tinham dormência e, mesmo assim, não foram prejudicadas pela imersão em ácido por até 90 min e que as sementes dos lotes 4 e 5 tinham dormência e foram favorecidas pela escarificação por até $90 \mathrm{~min}$, é possível inferir que o ácido sulfúrico até esse período de escarificação permite a superação da dormência sem prejudicar a germinação de sementes não dormentes.

Como a porcentagem de dormência foi maior nas sementes recém-colhidas em relação aos demais lotes, as sementes dos lotes 4 e 5 foram utilizadas para o aprimoramento do método, visando à definição do tempo

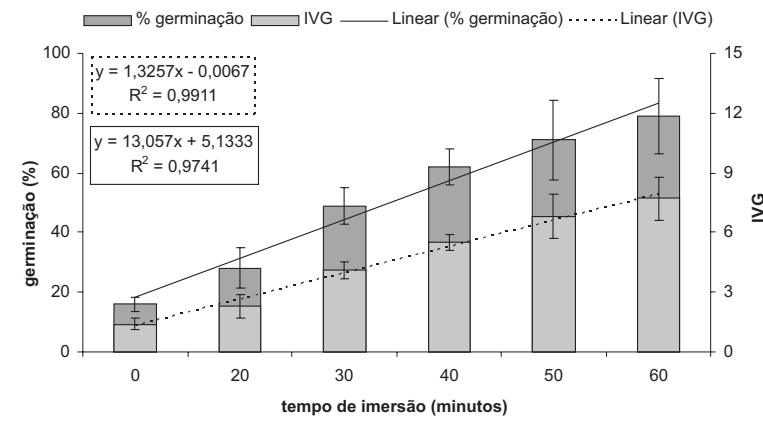

Figura 2 - Sementes recém-coletadas de saguaraji-vermelho (Colubrina glandulosa Perk.), lote 4: relação entre o tempo de imersão das sementes em ácido sulfúrico e a porcentagem e velocidade de germinação. As linhas verticais representam o desvio-padrão.

Figure 2 - Recently harvested Colubrina glandulosa Perk. seeds, lot 4: relations between seeds immersion time in sulfuric acid, germination percentage and speed. Vertical lines represent the standard deviation. mais adequado de escarificação química da semente. Tanto no lote 4 (Figura 2) quanto no lote 5 (Figura 3) houve aumento diretamente proporcional da velocidade e porcentagem de germinação em relação ao período de escarificação, com valores máximos desses parâmetros para $60 \mathrm{~min}$.

Como a imersão das sementes de saguaraji-vermelho em ácido sulfúrico por 60 min resultou em valores significativamente superiores de percentagem e velocidade de germinação ao considerar todos os lotes testados em conjunto, esse período foi considerado como o mais indicado para a escarificação química das sementes dessa espécie.

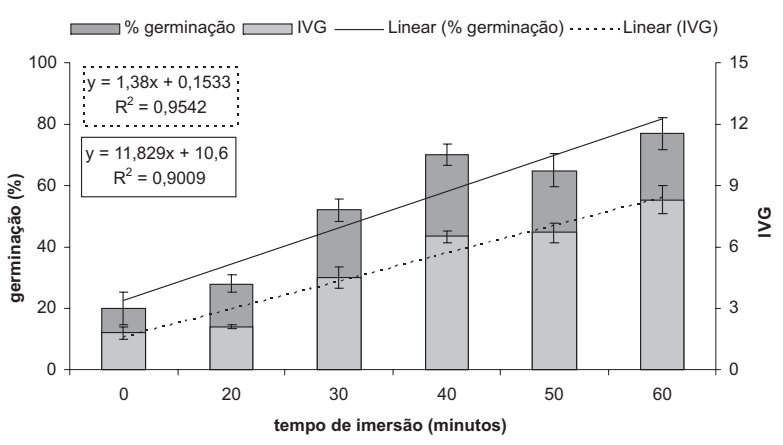

Figura 3 - Sementes recém-coletadas de saguaraji-vermelho (Colubrina glandulosa Perk.), lote 5: relação entre o tempo de imersão das sementes em ácido sulfúrico e a porcentagem e velocidade de germinação. As linhas verticais representam o desvio-padrão.

Figure 3 - Recently harvested Colubrina glandulosa Perk. seeds, lot 5: relations between seeds immersion time in sulfuric acid, germination percentage and speed. Vertical lines represent the standard deviation. 
De forma semelhante, resultados de pesquisa obtidos com sementes de espécies florestais nativas têm demonstrado que a imersão das sementes em ácido sulfúrico por períodos de 50 a 60 min é favorável para a superação da dormência (LOPES et al., 1998; ARAÚJO NETO et al., 2000; CRUZ et al., 2007). Contudo, cada espécie em particular pode demandar período específico de escarificação das sementes, resultado de diferenças na espessura e constituição química do tegumento.

Apesar de o ácido sulfúrico poder ser utilizado com sucesso na escarificação química de sementes, principalmente em análises laboratoriais de viabilidade, algumas dificuldades restringem sua utilização em larga escala em viveiros florestais, tal como a dificuldade de aquisição do ácido, possibilidade de acidentes durante o manuseio e destinação adequada dos resíduos gerados. Nesse contexto, o armazenamento das sementes pode ser alternativa viável para a superação da dormência.

Embora parte das sementes possa se deteriorar durante o armazenamento, a porcentagem de germinação dessas sementes (em torno de 50\%) foi superior à apresentada por sementes recém-colhidas e semeadas sem algum tratamento para a superação da dormência.

Assim, o armazenamento das sementes de saraguajivermelho por um ano e a imersão em ácido sulfúrico concentrado por 30 a 90 min podem ser utilizados para a superação da dormência.

\section{AGRADECIMENTOS}

Aos viveiros florestais Bio Flora e Câmara, pela cessão das sementes.

\section{REFERÊNCIAS}

ALBUQUERQUE, M. C. F. et al. Influência da temperatura e do substrato na germinação de sementes de saguaraji-vermelho (Colubrina glandulosa Perk. - Rhamnaceae). Revista Brasileira de Sementes, v.20, n.2, p.346-349, 1998.

ARAÚJO NETO, J. C.; AGUIAR, I. B. Tratamentos pré-germinativos para superar a dormência de sementes de Guazuma ulmifolia Lam. Scientia Forestalis, n.58, p.15-24, 2000.

CARVALHO, P. E. R. Espécies florestais brasileiras: recomendações silviculturais, potencialidades e uso da madeira. Brasília: CNPF-Embrapa, 1994. 640p. v.1.
CRUZ, E. D.; CARVALHO, J. E. U.; QUEIROZ, R. J. B. Scarification with sulfuric acid of Schizolobium amazonicum Huber ex Ducke seeds - Fabaceae. Scientia Agrícola, v.64, n.3, PAGINAS, 2007.

EIRA, M. T. S.; FREITAS, R. W. A.; MELLO, C. M. C. Superação da dormência de sementes de Enterolobium contortisiliquum (Vell.) Morong. Leguminosae. Revista Brasileira de Sementes, v.15, n.2, PAGINAS, 1993.

FERREIRA, A. G.; JOÃO, K. H. L.; HEUSER, E. D. Efeitos de escarificação sobre a germinação e do $\mathrm{pH}$ no crescimento de Acacia bonariensis Gill e Mimosa bimucronata (D.C.) O.K. Revista Brasileira de Fisiologia Vegetal, v.4, n.1, p.63-65, 1992.

FORSYTHE, C.; BROWN, N. A. C. Germination on the dimorphic fruits of Bidens pilosa L. New Phytologist, v.90, p.151-164, 1982.

FOWLER, J. A. P.; BIANCHETTI, A. Dormência em sementes florestais. Colombo: Embrapa Florestas, 2000. 27p. (Embrapa Florestas. Documentos, 40).

GLADSTONES, J. S. Lupinus as crop plants (review article). Field Crop Abstracts, v.23, p.123-148, 1970.

HENDRIX, S. D. Variation in seed weight and its effects on germination in Pastinaca sativa (Umbeliferae). American Journal of Botany, v.71, p.795-802, 1984.

LOPES, J. C. et al. Germinação de sementes de espécies florestais de Caesalpinea férrea Mart. ex Tul. var. leiostachya Benth., Cassia grandis L. e Samanea saman Merrill, após tratamentos para superar dormência. Revista Brasileira de Sementes, v.20, n.1, p.80-86, 1998.

LOPES, J. C.; DIAS, P. C.; MACEDO, C. M. P. Tratamentos para acelerar a germinação e reduzir a deterioração das sementes de Ormosia nitida Vog. Revista Árvore, v.30, n.2, p.171-177, 2006.

LORENZI, H. Árvores brasileiras: manual de identificação e cultivo de plantas arbóreas do Brasil. 4.ed. Nova Odessa: Instituto Plantarum, 2002. v.1. 368p.

Revista Árvore, Viçosa-MG, v.35, n.1, p.119-124, 2011 
MAGUIRE, J. D. Speeds of germination-aid selection and evaluation for seedling emergence and vigor. Crop Science, v.2, p.176-177, 1962.

MARCOS FILHO, J. Fisiologia de sementes de plantas cultivadas. Piracicaba: Fealq, 2005. 465p.

MAUN, M. A.; PAYNE, A. M. Fruit and seed polymorphism and its relation to seedling growth in the genus Cakile. Canadian Journal of Botany, v.67, p.2743-2750, 1989.

OLIVEIRA, L. M.; DAVIDE, A. C.; CARVALHO, M. L. M. Avaliação de métodos para a quebra da dormência e para a desinfestação de sementes de canafístula (Peltophorum dubium (Sprengel) Taubert). Revista Árvore, v.27, n.5, p.597-603, 2003.

QUEIROZ, M. H. Triagem densiométrica e quebra de dormência em Colubrina glandulosa Perkins var. reitzii (M.C. Johnston) M.C. Johnston. Silvicultura em São Paulo, v.16, n.1, p.307-311, 1982.
QUEIROZ, R. M.; MATOS, V. P.; ANUNCIAÇÃO FILHO, C. J. Variação do grau de dormência em sementes de Stylosanthes scabra de três regiões ecogeograficas do Estado de Pernambuco. Revista Brasileira de Engenharia Agrícola e Ambiental, v.4, n.3, p.416-420, 2000.

RAMOS, A.; ZANON, A. Dormência em sementes de espécies florestais nativas. In: SIMPÓSIO BRASILEIRO SOBRE TECNOLOGIA DE SEMENTES FLORESTAIS, 1., 1984, Belo Horizonte. Anais. Brasília: ABRATES, 1986. p.241-265.

SMIDERLE, O. J.; SOUSA, R. C. P. Dormência em sementes de paricarana (Bowdichia virgilioides Kunth- Fabaceae-Papilionideae). Revista Brasileira de Sementes, v.25, n.1, p.72-75, 2003.

ZONTA, E. P.; MACHADO, A. A. Sistema de análise estatística para

microcomputadores-SANEST. Pelotas: 1984. 109p. 